Garcés-Mora, J. (2019). Arte, patrimonio y la pérdida de conocimiento de la pintura de caballete en Colombia. Construcción de un sistema integrado de información. Revista de Antropología y Sociología: VIRAJES, 21(2), 103-132. DOI: 10.17151/rasv.2019.21.2.6

\title{
Arte, patrimonio y la pérdida de conocimiento de la pintura de caballete en Colombia. Construcción de un sistema integrado de información
}

\section{JHON GARCÉS-MORA**}

Recibido: 2 de febrero de 2019

Aprobado: 29 de abril de 2019

Artículo de investigación

\footnotetext{
* Microbiólogo industrial. Docente de la Facultad de Estudios de Patrimonio Cultural e investigador del Grupo Estudios del Patrimonio Cultural en Colombia de la Universidad Externado de Colombia. Bogotá D.C, Colombia. E-mail: jhon.garces@uexternado.edu.co. (ㄱ) ORCID: 0000-0002-9672-2790. Google Scholar
} 


\title{
Resumen
}

Con el fin de contribuir a las humanidades digitales y acceso abierto, se planteó el diseño y desarrollo de un Sistema de Información Científica de Arte y Patrimonio (SICAP) para la creación de bancos de información de conocimiento científico, documentación producida en labores de restauración de pinturas de patrimonio material colombiano. Esperando recuperar la información disociada, de 20 años de investigación sobre pinturas de caballete en especial los análisis con rayos $\mathrm{X}$ junto con análisis microquímicos, caracterización de lienzos, cortes estratigráficos e información de pigmentos, en una única base de datos relacional, diseñada para el acceso público.

Uno de los mayores retos para la gestión del patrimonio cultural, particularmente para la investigación y conservación, es divulgar los resultados de los diagnósticos, estudios y análisis realizados sobre el patrimonio material; documentación a la que además se suma el problema del deterioro, pérdida y falta de acceso de los archivos físicos.

Palabras clave: humanidades digitales, sistemas de información, arqueometría, ciencias de la conservación, patrimonio cultural y pintura de caballete.

\section{Art, heritage and the loss of knowledge on easel painting in Colombia. Construction of an integrated information system}

\begin{abstract}
In order to contribute to the digital humanities and open access, the design and development of a system called SICAP (Scientific Information System for Art and Heritage, for its acronym in Spanish) for the creation of databases of scientific knowledge, documentation produced in restoration work of Colombian material heritage paintings was suggested. This, with the purpose to recover the dissociated information of 20 years of research on easel painting, especially X-ray and micro chemical analysis, characterization of canvases, stratigraphic cuts and pigment information in a single relational database, designed for public access.

One of the greatest challenges for the management of cultural heritage, particularly for research and conservation, is to disseminate the results of the diagnoses, studies and analyses performed on material heritage, a documentation that also adds to the problem of deterioration, loss and lack of access to physical files.
\end{abstract}

Key words: digital humanities, information systems, archaeometry, conservation sciences, cultural heritage, easel paintings. 


\section{Introducción}

— 1 presente artículo muestra los resultados de un proceso de investigación académica, que surge dentro del contexto de la Maestría en Patrimonio Cultural de la Universidad Pedagógica y Tecnológica de Colombia, dirigido por la antropóloga Monika Therrien.

El ejercicio de investigación surge de interés personal, así como una respuesta al problema generalizado en muchos centros de producción de conocimiento, de cómo poner a disposición de un público amplio, los resultados científicos que se obtienen en las investigaciones, sin que se queden archivados o no puedan servir de base para otros proyectos o investigadores. Este comenzar siempre desde ceros, resulta particularmente grave para el campo del patrimonio cultural mueble, en tanto los estudios técnicos e investigaciones que se han realizado a las pinturas, esculturas y en general, a obras de gran trascendencia para la historia del arte colombiano, involucran la toma de muestras y comprometen la materialidad de las propias obras. En ese sentido, el trabajo de la Universidad Externado de Colombia, en convenio con el Ministerio de Cultura, ligado al desarrollo del programa de formación en conservación y restauración de bienes muebles, constituye a través del Laboratorio de Ciencias de la Conservación un acervo único de muestras físicas e informes de resultados que constituyen un caso de estudio excepcional para abordar el problema de investigación.

En el transcurso de la formulación del proyecto que inició desde 2017 se planteó como objetivo general el diseño y creación de un sistema de información que permitiera, por un lado, articular la información científica dispersa producto de casi 30 años de investigación, y por otro, poner a disposición de diferentes públicos esta información.

Este proceso, más allá de los desafíos técnicos que implica diseñar una herramienta de este tipo, implicó pensar en una propuesta o aproximación metodológica que, aunque no es novedosa, lo es en el sentido específico de cómo crear bases de datos ajustadas a los requerimientos de estudio del patrimonio cultural que para este caso, abordó la necesidad de cómo relacionar información iconográfica, con resultados de análisis científicos y radiografías que develan el uso de pigmentos y en una escala más amplia, la grafía de los artistas.

Teniendo en cuenta que existen bases de datos en contextos de arte y patrimonio con sus limitaciones, por ejemplo el caso en México con la Escuela Nacional de Conservación, Restauración y Museografía Manuel del Castillo Negrete (ENCRyM) del Instituto Nacional de Antropología e Historia, quienes desarrollaron una base de datos denominada SOPHIA para estudios de los materiales constitutivos de la escultura policromada, 
la cual busca ordenar y sistematizar la extensa información generada en el proceso pedagógico que se lleva a cabo en los seminarios de la ENCRyM. Sin embargo, el proyecto presenta dos factores limitantes: que su consulta y uso sea a través de intranet; y que por medio de códigos internos de la ENCRyM se localicen los informes en la biblioteca (Chagoyán, Coronel y Figueroa, 2013).

En Estados Unidos la Universidad de California Davis, diseñó y desarrolló colecciones digitales con el proyecto PESSCA, con cerca de 4600 pinturas de arte colonial español, al hacer emparejamientos entre los grabados de arte colonial español con las pinturas realizadas por artistas coloniales, liderando un esfuerzo de colaboración internacional con la Pontificia Universidad Católica del Perú, para seguir ampliando la base de datos con las contribuciones que pueden hacer investigadores, coleccionistas, conservadores, curadores, comerciantes y otros entusiastas del arte colonial español. A pesar de los esfuerzos, el sistema carece de información más especializada en lo que respecta al tipo de técnica, siendo muy visual mostrando la riqueza del grabado y la pintura elaborada por artistas locales.

En Canadá, hicieron una base de datos llamada Baroque-art (Suárez y Sancho, s.f.), financiada por el Consejo de Investigación de Ciencias Sociales y Humanidades de este país, y corresponde a una recopilación de datos de pintores y pinturas del barroco hispánico de 1550 a 1850 realizado por el Laboratorio CulturePlex en la Universidad de Western Ontario, con una muestra de 12.000 imágenes, la gran mayoría europeas. La base de datos se enfoca en el análisis a múltiples escalas conteniendo datos como la información biográfica del artista, ubicación original y actual de la obra, así como un mapa que provee una visualización de las pinturas en configuraciones espaciales y temporales.

Sin embargo, esta página ya no se encuentra disponible y la URL http://www.cultureplex.ca/project/the-baroque-art-project-at-your-service/ fue hackeada, y envía a un sitio no seguro de citas en línea.

En Colombia desde 1990 hasta 1995, el extinto Centro Nacional de Restauración Santa Clara (CNR de ahora en adelante) desarrollaba un sistema de información concerniente a los procesos de organización y representación del conocimiento (ORC), que funcionaba con el sistema operacional DOS versión 3,3. Con él se ordenaban los datos al agrupar tipologías referentes a la identificación de los materiales utilizados en 365 pinturas de caballete en el Nuevo Reino de Granada de obras firmadas o atribuidas a un artista o referenciadas como autor desconocido, que por su valoración estética pertenecían a los siglos XVI, XVII, XVIII y XIX (Rodríguez, 1995). 
Sin embargo, cuando cerraron el laboratorio en 1997, tras un largo periodo de dificultades financieras y técnicas, se desmantelaron las instalaciones donde se realizaban los análisis químicos y las placas de rayos $X$. De la base de datos, la información fue supeditada a un sistema operacional que nunca se migró hacia nuevas tecnologías, quedando dos tomos impresos sin paginar con tablas de resultados sin imágenes.

Otro esfuerzo nacional fue realizado por el Departamento de Historia de la Universidad de los Andes desde 2015. El proyecto ARCA es una base de datos que contiene más de veinte mil imágenes de arte colonial americano (fechadas entre 1550-1830), pinturas que fueron ubicadas en la red y en bibliotecas e institutos patrimoniales de siete ciudades americanas. En este caso, ARCA cuenta con el apoyo de ingenieros de software y diseñadores webmaster quienes desarrollaron una primera etapa de preproducción que cuenta con 56 campos de preguntas para cada imagen, en la cual el eje es el análisis de la relación cuerpo-gesto; permitiendo además georreferenciación, línea de tiempo y descriptores complejos. A la base se accede mediante cuatro metabuscadores: temas iconográficos, autores, regiones y título de obra (Guerrero, Villaveces y Murcia, 2017).

De esta manera al hacer un barrido del uso de bases de datos para el estudio integral o relacional de la pintura en caballete en América, es posible ver cómo, a pesar de existir esfuerzos dispersos por integrar la información y ponerla al servicio del público, no existen hasta el momento sistemas que permitan una verdadera integración de los distintos tipos de datos que brinde la posibilidad de nuevos enfoques y análisis de la información existente.

Este punto es de gran importancia además, porque subyace un problema ético en la conservación del patrimonio puesto que, como se ha señalado y como se explicará más adelante, la información científica requiere de la toma de muestras físicas extraídas de esas pinturas de caballete (imagen 1), que puede causar la destrucción de contextos, alteración de obras o disociación; por otro lado, en muchos casos esas pinturas se han perdido o fueron hurtadas quedando tan solo la documentación técnica con sus respectivas fotografías.

De ahí la importancia y el valor de la información y de las muestras conservadas (cortes estratigráficos) como evidencia material en algunos casos única e irrepetible de una pintura de caballete que proviene de contextos locales, regionales y nacionales. Lo anterior hace que se gire alrededor de una pregunta central: ¿Por qué es necesario hacer investigación para construir estas herramientas que permitan aprovechar la información que existe? 
En ese sentido, cualquier proyecto que involucre el desarrollo de una base de datos debe sustentarse en una investigación que conlleva a la conceptualización y creación de categorías de análisis. Estas son las que van a constituir el fundamento de la herramienta que no solo sirve como medio de consulta, sino que incita a nuevas investigaciones a plantearse más interrogantes, puesto que al tener toda la información agrupada con fotografías y metadatos, que van de lo general a lo específico, se pueden deducir y comparar las obras firmadas por los artistas con aquellas que son atribuidas y que tienen cierta similitud en la técnica pictórica, entre una de sus potenciales aplicaciones para el análisis de pintura.

¿De dónde sale la información científica global, puntual e iconográfica de las pinturas, para el diseño y ajuste del SICAP? Se hizo una inmersión en la documentación producida por más de 30 años de trabajo en Colombia, realizados por el Laboratorio de Ciencias de la Conservación (LCC de ahora en adelante) de la Universidad Externado de Colombia, con análisis desde diferentes perspectivas que incluyen: bases de preparación, pigmentos, cortes estratigráficos y radiografías.

El LCC posee las muestras físicas del CNR tomadas a más de 350 obras de pintura de caballete con un alto valor científico (imagen 2), que se suman al banco de muestras físicas tomadas a 120 pinturas, que están asociadas a procesos académicos de los estudiantes ligados a los talleres de formación del pregrado en conservación y restauración de bienes muebles, así como a muestras de investigación de pinturas desde el siglo XVII hasta el siglo XX.

Pese a la importancia nacional de este banco de datos que incluye muestras físicas asociadas a cientos de informes técnicos y pese a tratarse de pinturas de caballete de un enorme valor para el conjunto de las colecciones y museos del patrimonio cultural en Colombia, teniendo en cuenta además que son análisis científicos financiados o apoyados desde el Ministerio de Cultura con recursos públicos, el acceso a esta información tan importante no es público y más grave aún, no se sabía cómo relacionar los distintos niveles de datos (fotografías generales, autor, época, iconografía) e información científica (naturaleza de lienzo, bases de preparación y pigmentos usados por el artista, etc.).

A este respecto y considerando que no existen recetas mágicas para construir este tipo de sistemas de información compleja, resulta necesario avanzar en un conocimiento aplicado para formular maneras de aproximarse y resolver este tipo de problemas de investigación. De esta manera, el propósito del SICAP se orienta a hacer accesible la información relacional sobre las placas radiográficas de pinturas de caballete, la clasificación de la naturaleza química y morfológica de las bases de preparación y pigmentos, 
con respecto a la iconografía de los temas representados en cerca de 500 años de pintura.

Con toda esa documentación técnica dispersa y disociada de las muestras tomadas de la pintura de caballete, uno de los desafíos técnicos de la investigación consistió en la digitalización, en consonancia con las tendencias marcadas por el patrimonio digital en la que se señala el “enfoque creciente en la digitalización de la cultura material y artefactos culturales como imágenes, objetos y textos [...] para la creación de bases de datos con fines de documentación y catalogación de colecciones digitales y repositorios en línea" (Lutz, 2018, p. 9); y que se relaciona con la reflexión crítica planteada por Vinck (2013) en tanto "con la digitalización de contenidos no se llegaría necesariamente a una democratización del conocimiento, como podría pensarse $[\ldots]^{\prime \prime}$ (p. 68).

Según lo argumenta Hayles (2012), esa colaboración entre académicos y profesionales de la variedad de disciplinas involucradas en los proyectos enmarcados en las humanidades digitales, se constituye en nuevas formas de investigar, gestionar, comprender la información y profundizar en el conocimiento. De ahí que, con la creación de un sistema de información, el LCC de la Universidad Externado de Colombia esté involucrándose en el tema de las humanidades digitales y su propuesta contemporánea, pues al digitalizar cuerpos documentales de ciencias naturales aplicadas al estudio de materiales de la pintura de caballete, ha logrado la codificación de los documentos que permiten profundizar en el conocimiento de las técnicas y desarrollo de la pintura de caballete en Colombia.

En su primera parte, este artículo, describe en detalle el tipo de información especializada con la que se trabajó: fotografías, análisis relacionados con el tipo de lienzo, bases de preparación usadas por el artista, tipo de pigmentos y su fecha de uso, cortes estratigráficos, la inserción de categorías iconográficas, además de exámenes globales y radiografías tomadas a las pinturas de caballete estudiadas e intervenidas en los talleres de la Universidad Externado de Colombia, entre 1998 y 2017 con el apoyo profesional y docente del LCC.

En la segunda parte, se aborda una contextualización histórica de algunos de estos análisis científicos realizados en Colombia a las pinturas de caballete, como una forma de situar a los lectores en el desarrollo de este tipo de investigaciones en nuestro país.

En la tercera parte se presenta el diseño conceptual dedicado al proceso de conceptualización, diseño y creación del Sistema de Información Científica de Arte y Patrimonio, SICAP. En este se explica cuál fue el enfoque metodológico utilizado en concordancia con la perspectiva de investigación conocida como teoría fundamentada y el análisis cualitativo de datos con 
el cual se hizo la construcción del esquema conceptual que da sustento al sistema.

En la cuarta sección se muestran algunas reflexiones en torno a lo que fue el análisis de resultados de la investigación y el progreso de la puesta en funcionamiento del SICAP como una herramienta correlacional de información.

Por último, al tratarse de una apuesta metodológica en donde más allá de saber si el SICAP funciona o no, resulta apresurado sacar conclusiones en una fase exploratoria, por lo cual se presentan algunas reflexiones y consideraciones finales que a mi parecer son de gran importancia para entender la propuesta de investigación.

\section{Datos, obras y ciencias}

Para la construcción del SICAP se revisaron las fuentes de documentación (fichas e informes) que reposan en la estantería del laboratorio de la Facultad de Estudios del Patrimonio Cultural de la Universidad Externado de Colombia; se verificó que la información estuviera completa, con microfotografías e informes en plano digital. Además, en el centro de documentación de la facultad se revisaron las fotografías de las 120 obras intervenidas; 110 de estas pinturas elaboradas entre los siglos XVII y XIX son de dominio público; y 10 obras del siglo XX de las que se deberá buscar entre familiares del artista la autorización de divulgación en la red. Estas pinturas cuentan con radiografías que se encuentran en físico para su digitalización y reutilización en el SICAP y posterior inclusión en la biblioteca digital de la universidad.

\section{Fotografías a blanco y negro}

En los talleres de formación de pregrado realizados en la facultad entre 1999 y 2001 se utilizaron 82 fotografías a blanco y negro de tamaño de $20 \times 25 \mathrm{~cm}$, con las cuales se documentaron los informes técnicos y las llamadas historias clínicas con información gráfica de los análisis globales realizados: luz rasante y fluorescencia UV, hasta la entrega a su custodio con fotografías finales de la obra ya restaurada.

De otro lado, en el centro de documentación de la facultad se conservan 741 fotografías, reveladas hasta 2008 en papel fotográfico, que están protegidas dentro de álbumes, en carpetas libres de ácido que garantizan la preservación y el uso cuando se requieran. Para el caso del SICAP, se revisaron 617 fotografías escaneadas por el centro de documentación, con el fin de escoger las imágenes del anverso de la pintura antes y después de 
la restauración y así insertarlas en el correspondiente apartado del SICAP que se refiere a la información general de la obra, en donde además se especifican las dimensiones que tiene la pintura.

\section{Fotografías a color}

Entre 1999 y 2008 fueron tomadas 367 fotografías, impresas a color por fotógrafos profesionales. Estas sirvieron para la documentación de los talleres de intervención de pintura de caballete mejorando hasta cierto punto la calidad de imagen observada en los análisis globales. Por ello, la importancia de llegar a preservar esta información fotográfica de pinturas de caballete de los siglos XVII a XX en un sistema de información científica que pueda divulgarse en la red.

\section{Estudios morfológicos, análisis de fibras}

Para identificar las fibras presentes en los soportes de tela de la pintura de caballete se acude al análisis microscópico que comprueba propiedades morfológicas. Los resultados de los análisis de soporte se han articulado dentro del SICAP para lograr difundir vía web, la caracterización de los lienzos de las 120 pinturas fechadas entre los siglos XVII y XX que hacen parte del SICAP.

Teniendo agrupados los datos en una base plana, los usuarios pueden identificar la naturaleza de la fibra para las 111 pinturas de caballete, la cual corresponde a 83,8 \% de lino y 15,7 \% de algodón, así como obras del siglo XIX en la que los resultados refirieron un soporte en el cual los hilos de la trama están conformados por fibras de lino y los de la urdimbre de yute $0,9 \%$. Estos resultados, por ejemplo, no han sido referenciados dentro de la historia del arte colombiano para las pinturas de la época colonial neogranadina.

\section{Bases de preparación}

Respecto a las bases de preparación que fueron analizadas en el LCC, de 57 obras de pintura de caballete que se insertaron en la base de datos SICAP, se clasificaron los resultados de los materiales usados entre los siglos XVII al XX, encontrando en algunas de las obras hasta dos bases de preparación en una misma pintura.

$\mathrm{Al}$ tener la información asociada, el SICAP permite hacer estudios comparativos entre artistas o autores de inicios de siglo XVII. Estas deducciones se hicieron por ejemplo con el reconocido pintor Antonio 
Acero de la Cruz (imagen 3), quien utilizaba bases de preparación rojas, compuestas por tierra roja (imagen 4), mientras que Juan Bautista Vásquez (imagen 5), hermano mayor de Gregorio Vásquez de Arce y Ceballos, usaba bases de preparación amarillas con ocre amarillo (imagen 6), tal y como las utilizó a la vez su mentor don Baltasar Vargas de Figueroa.

A propósito y según los estudios realizados sobre pintura de caballete en el Instituto de Física, Universidad Nacional Autónoma de México (IFUNAM), el doctor en ciencias José Ruvalcaba (2008) señala el tipo de comparaciones que se pueden realizar con pinturas fechadas o autores atribuidos: "cuando se tiene una composición temporal característica de los materiales o bien una manera de relacionar una composición fechada con una no fechada es posible realizar análisis comparativos y por lo tanto estudios de cronologías absolutas y relativas" (Ruvalcaba, 2008, p. 166).

De ahí que se proponga dentro del SICAP, en el apartado de bases de preparación, campos prestablecidos con el uso de cada uno de los pigmentos inorgánicos utilizados en las pinturas de caballete intervenidas en los talleres de restauración de la universidad.

\section{Cortes estratigráficos}

La estratigrafía es la superposición de estratos, según el proceso de elaboración de las obras de caballete; así se denomina el conjunto total de estratos. Con este análisis se visualizan las capas pictóricas que presentan varias constantes y algunas variables que dependen del artista y la época en la cual fueron elaboradas.

Al seguir un patrón cada corte se asimila a una huella dactilar, detallando el grosor de la base de preparación y las capas pictóricas. Se tienen resultados de 390 cortes de las 118 pinturas de caballete. Se mejoraron e insertaron microfotografías de la estratigrafía (imágenes 7 y 8) y se incluyeron campos que describieran la naturaleza de cada capa pictórica y el tipo de aglutinante utilizado por el artista, ya fuese pintura al aceite (óleo) o con proteínas (temples).

\section{Análisis de pigmentos}

El análisis de pigmentos es el complemento de los cortes estratigráficos y del análisis de aglutinantes, pues posibilita identificar la naturaleza de los pigmentos presentes en la obra y sus mezclas. En algunos casos sirve para determinar la autoría de la obra pictórica: "la identificación de pigmentos en las obras de arte (...) sirve para distinguir las partes de las obras originales, 
y aquellas partes que han sido restauradas, ya que cada época ha utilizado distintas composiciones en la confección de los colores" (Giró, 2010, p. 213).

Este análisis permite, junto con la comparación con datos históricos, la posible datación de obras de forma indirecta. Sobre todo, con los pigmentos industriales, pues cuenta con las referencias e información concerniente a su descubrimiento y periodo de uso o en algunos casos, las fechas en las que fueron prohibidos por distintas razones y salieron del mercado del arte, marcando también una datación terminal.

De las 120 pinturas de caballete utilizadas en el SICAP, el químico Javier Uribe identificó la naturaleza de los pigmentos, tras observar al microscopio las reacciones microanalíticas en 94 obras de caballete que hacen parte de las capas pictóricas. Se hallaron 40 pigmentos diferentes que fueron utilizados en las pinturas para darle fondo y recreaciones a cada uno de los temas iconográficos estudiados. En su totalidad fueron 110 combinaciones identificadas, ordenadas e insertadas en el formulario como campo fijo del SICAP; esto se complementa con información de la fecha extrema de uso y con los otros nombres con los que se reconoce dicho pigmento, por ejemplo: al blanco de plomo, se le conoce también con el nombre de Albayalde y fue utilizado desde el siglo I d. C. hasta el siglo XIX.

De allí que la naturaleza química, el color y las fechas terminales de uso, vienen siendo insumos para que cada investigador pueda construir relaciones socioculturales, dilucidar qué pigmentos eran importados, cuál era su valor económico. Es así por ejemplo que en las interpretaciones hechas por Vargas (2012), al analizar fuentes primarias de los archivos históricos, llega a esclarecer el hilo cronológico de las imágenes en la colonia a partir de los resultados de la naturaleza del pigmento, logrando referir o clasificar la paleta de color de los artistas o talleres de la época.

\section{Temas iconográficos, como complemento para el estudio integral de pinturas}

Adicionalmente, así como existen categorías técnicas que sustentan los análisis científicos realizados a la pintura de caballete, también se tuvo en cuenta para el diseño del SICAP la iconografía representada en cada pintura estudiada. Hasta principios del pasado siglo, los historiadores del arte se enfrentaban al estudio de la pintura con su ojo, una lupa de aumento y en ocasiones, con buenas reproducciones de las obras en blanco y negro. En los primeros años del siglo XX: 
La investigación en historia del arte comenzó a enriquecerse con las nuevas lecturas que permitían hacer exámenes llevados a cabo con fuentes de radiación más energéticas que la visible -rayos $X$, rayos infrarrojos y ultravioletas- que revelaban aquello que no podía captar la visión humana. (González, 2013, p. 163)

El equilibrio entre los análisis iconográficos y los análisis globales, así como de la naturaleza química de la pintura de caballete, el investigador puede encontrar una buena interpretación delos resultados, constituyéndose en información valiosa para la toma de decisiones adecuadas con respecto a la intervención de la obra, así como de datos para complementar y profundizar en el patrimonio material estudiado.

Las imágenes religiosas provenientes de España durante el proceso de evangelización adquirieron gran significación en los territorios conquistados, forjando contextos geográficos locales, regionales y nacionales de gran devoción, mediación y uso. Estas adquirieron fuerza, sedujeron poblaciones enteras, transmitieron un mensaje y así llegaron hasta nuestros días: Santos, Mártires, Vírgenes, pinturas Cristológicas, Apóstoles, etc. (Borja, 2013). Estas imágenes fueron los referentes iconográficos de mayor envergadura y reproducción instaurados en el Nuevo Reino de Granada.

Los estudios interdisciplinarios entre los análisis científicos y los análisis iconográficos logran complementarse y contribuir a la revisión de nuevas interpretaciones. Es el caso del trabajo realizado por Vargas (2012), al analizar las fuentes de información para el estudio de la pintura en el Nuevo Reino de Granada, entre 1552 hasta 1813. Esa pesquisa minuciosa de documentos en archivos, inventarios y materiales elementales, afirma la necesidad de incluir esta categoría en el diseño del SICAP como una herramienta que enriquece la conservación, la intervención y la transmisión del patrimonio cultural colombiano.

Derivado de lo anterior, en el SICAP se clasificaron las imágenes con relación a ocho temas iconográficos, los que emergieron a partir de la revisión de las 120 pinturas de caballete que contaban con placas radiográficas. Estos temas se ajustaron en concordancia con los cientos de informes asociados, producidos desde 1999 hasta la actualidad en la Universidad Externado de Colombia.

Como resultado de la revisión y cuantificación, se identificaron los temas iconográficos de las pinturas de caballete más estudiadas y analizadas en el LCC e intervenidas en los talleres de restauración de la Universidad Externado de Colombia: 1) Santos y santas (47,5\%), 2) Retratos $(24,2 \%)$, 3) Advocaciones marianas (18,3\%), 4) Historia (4,2 \%), 5) Cristológico (3,3 \%), 6) Ángeles y arcángeles (0,8\%), 7) Escudos (0,8 \%) y 8) Paisajes (0,8\%). 
Radiografías

En el estudio de una obra de pintura de caballete, con el aprovechamiento de la información obtenida con radiografías, en ocasiones se logra analizar con mayor nitidez la pincelada, su dirección, o su tamaño (grosor, largura) las técnicas de aplicación de la base de preparación, pigmento, así como detallar faltantes o arrepentimientos. En ocasiones, se comprobará que los pintores han utilizado los soportes que podían ser de otros artistas o simplemente de obras ya usadas y reutilizadas (Ineba, 2010). Ejemplo de ello son las imágenes expuestas en la imagen 9, insertadas en el SICAP.

Al revisar la documentación técnica, en lo correspondiente a la información gráfica se hallaron 211 radiografías en físico de diversos tamaños o formatos (43 cm x $35 \mathrm{~cm}, 35 \mathrm{~cm} \times 33,5 \mathrm{~cm}, 25,5 \mathrm{~cm} \times 35 \mathrm{~cm}$ y $21,5 \mathrm{~cm} \times 35,5 \mathrm{~cm}$ ) asociadas a los análisis complementarios realizados a 79 obras de pintura de caballete estudiadas en los talleres de restauración. Para ello, las radiografías se digitalizaron para su posterior uso como información científica complementaria en la base de datos.

\section{Breve historia del uso de radiografías aplicadas al estudio del arte en Colombia}

En Colombia existen pocos expertos, investigadores e instituciones dedicados a los estudios con radiografías en bienes culturales muebles. En la mitad de la década de 1970, en el Centro de Restauración de Colcultura ${ }^{1}$, la restauradora María Cecilia Álvarez White logró organizar la sala de Rayos X junto con Hernando Morales, médico radiólogo especializado en el British Museum, y con la colaboración de Federico Guidobaldi, químico italiano. Ellos empezaron a hacer radiografías de centenares de pinturas en lienzo, especialmente de la época colonial, las cuales habían sido hechas por encargo y realizadas en su mayoría por autores desconocidos (Vidal, 2012).

Hacia 1979, la mayoría de las investigaciones relacionadas con estudios y aplicaciones de la radiografía en conservación-restauración, las había realizado el médico especialista en radiología y asesor del Centro Nacional de Restauración (CNR) de Santa Clara Hernando Morales Garzón, a la par de otra colega, la médica radióloga Cristina Arango de

\footnotetext{
${ }^{1}$ Instituto Colombiano de Cultura (Colcultura), creado en 1968 mediante Decreto-ley 3154, como la propuesta institucional y desde su organización como instituto del Ministerio de Educación, encargado de definir e impulsar políticas culturales en Colombia y de agrupar instituciones culturales del Estado que estaban dispersas en diversos organismos (Bravo, 2008). Colcultura fue el embrión del Ministerio de Cultura creado mediante la Ley 397 de 1997 “Ley General de Cultura” (De Norden, 2014).
} 
Valderrama; ellos hicieron más de 4000 radiografías (Pesantez, 2001). En el estudio de radiología realizado a la pintura santafereña del siglo XVII, Morales y Arango (1979) observaron el tipo de tejido en el que fue realizado el lienzo y, en algunos casos, la forma de unión de las piezas de tela cuando se trataba de obras de gran formato para las que se habían usado dos o más telas.

En 1993, la restauradora Álvarez White también abordó la discusión sobre los beneficios de este análisis. En Los rayos X y el arte, estudios de autoría, Álvarez (2005) describe cómo a partir del método investigativo basado en el análisis de la grafía pictórica del autor — algo así como la huella digital que el artista imprime en sus cuadros- por medio de la radiología y comparaciones con obras firmadas se logra acercar al artista que concibió la obra pictórica.

Durante casi dos décadas, la experticia en el uso de rayos $\mathrm{X}$ o toma de placas radiográficas al patrimonio mueble quedó relegada en estos profesionales; de ahí que al término de sus contratos con el CNR el análisis radiográfico fuera igualmente suspendido. Desafortunadamente, quienes tienen algún tipo de formación en el área de radiología, son expertos que rara vez están en contacto con el campo de la conservación o restauración, y en ese momento, no había otros profesionales a quienes capacitar para garantizar el relevo de los profesionales.

Desde 1980 hasta 1993, paralelamente a este trabajo con las radiografías, se formaron profesionales en restauración en el CNR,

Gracias a la inversión estatal y a los aportes de la cooperación internacional (...) que contó con el apoyo del Programa de las Naciones Unidas para el Desarrollo, de la OEA, del ICCROM y del Getty Conservation Institute lo cual perduró hasta 1993. (Lleras, 2014, p. 384)

Pero tras un largo periodo de dificultades financieras y técnicas, el CNR fue clausurado por el Ministerio de Cultura en 2003.

A su vez, se desmanteló el laboratorio donde se realizaban las placas de rayos $X$ con un aparatoso equipo instrumental, el cual devino en desuso por obsoleto. Parte de su información quedó en los dos centros de documentación, el de la Universidad Externado de Colombia y otra parte en el Ministerio de Cultura, gracias al convenio interinstitucional entre las dos entidades vigente desde 1994, donde reposan documentos en físico y algunas radiografías realizadas a esculturas policromadas; en la actualidad se desconoce el paradero de las placas radiográficas tomadas a la pintura de caballete. 


\section{Diseño conceptual del SICAP}

El enfoque metodológico utilizado para el diseño del SICAP (imagen 10) fue realizado a partir del análisis de la información siguiendo un modelo mixto entre el análisis de datos cualitativos y la teoría fundamentada, desarrollada por Glaser y Strauss en 1967 y que se fue ampliando y actualizando su uso para diversos ámbitos disciplinares.

Según lo argumentado por Giraldo (2011), este tipo de teoría tiene aplicación en los sistemas de información y con su estudio concluye lo siguiente,

La teoría fundamentada es una herramienta metodológica cuya finalidad es la construcción de teoría a partir de un conjunto de datos empíricos, por lo tanto, demanda mucho esfuerzo y trabajo porque basado en el método de la comparación constante se tiene que hacer recolección y análisis de datos una y otra vez hasta llegar al punto de la saturación para dar paso a la elaboración de conceptos que permita el surgimiento de la teoría. (p. 85)

Para este caso, se tradujeron los conceptos de la teoría fundamentada para la construcción de la metodología y de la herramienta virtual con miras a la producción de conocimiento. Basado en lo explicado por Strauss y Corbin (2002), con la teoría fundamentada se busca que cada usuario pueda utilizar el método comparativo constante, puesto que, al tener toda la información científica asociada en un mismo sistema, como lo es el SICAP, se puedan codificar y analizar datos en forma simultánea y que de allí emerjan conceptos técnicos. De esta manera, el investigador al tener interacción permanente con los datos extraídos de cada una de esas pinturas de caballete de los siglos XVI al XX y al hacer el procesamiento sistemático de los datos empíricos, logre abstraer e interpretar los resultados de los análisis científicos y construya sus propias conjeturas, hipótesis y conceptos.

Para acometer el propósito de divulgar la información referente al patrimonio artístico e histórico nacional y convertirla en el fundamento de futuras investigaciones e intervenciones, la primera labor consistió en la construcción del esquema mental. Se inició con base en estos datos sueltos suscritos en cada uno de los informes técnicos para luego consolidarlos en el SICAP, "en un esquema [que] refleja la información de manera secuencial y da prioridad a los conceptos abstractos" (Arellano y Santoyo, 2009, p. 48).

En el mapa mental se da a conocer el contexto del que proviene la información y la razón por la cual se justifica la necesidad de un sistema de información científica que pueda ser divulgado en la red. Ello, debido a 
que desde un inicio no se trata de un proceso de digitalización de fuentes; al contrario, lo que se busca es realizar la organización de los documentos, con la finalidad de proponer varios criterios de búsqueda sobre la información contenida en las fichas e informes de análisis científicos.

Para la creación del SICAP se planteó un esquema conceptual de base para la organización, categorización y análisis de correlación de la documentación técnica del patrimonio artístico colombiano estudiado en la Universidad Externado de Colombia y en este sentido, los diversos exámenes efectuados sobre las pinturas de caballete se configuran como categorías de análisis que entre sí permiten co-relacionar y analizar los resultados; es decir, el SICAP no solo permite reunir y divulgar la información, sino construir análisis a partir de las relaciones posibles basadas en el diseño de los criterios de búsqueda con que se construyó el sistema.

\section{SICAP, como herramienta de correlación e interpretación}

Al hacer la revisión y correlación con los temas y campos de información que contiene el SICAP, el siguiente paso fue empalmar los datos generales y científicos en otra hoja de cálculo en donde se incluyeron columnas y celdas en las que se transcribieron las descripciones e interpretaciones de cada placa radiográfica.

Con este propósito, se usaron técnicas de análisis cualitativo que llevarán a identificar cada concepto referenciado de acuerdo con su prevalencia en las transcripciones e interpretaciones de los resultados de los rayos $\mathrm{X}$.

En la revisión de las interpretaciones efectuadas en las placas de radiografías, se identificaron 12 categorías que se repiten, semejan y distinguen entre sí: 1) técnica de ejecución (70\%); 2) repintes (20\%); 3) utilización de pigmentos a base de blanco de plomo (8\%) (imagen 11); 4) atribución a una escuela o artista en específico (1\%); 5) evidencia de faltantes (18\%); 6) injertos (3\%); 7) arrepentimiento por parte del artista o pentimentos (15\%); 8) formas de aplicación de las bases de preparación $(8 \%) ; 9)$ intervenciones anteriores $(8 \%) ; 10)$ la aparición de imágenes debido al oscurecimiento del barniz $(1 \%) ; 11)$ dibujo subyacente $(6 \%)$, el cual se encuentra relacionado con la última categoría; 12) la reutilización de soportes o lienzos (4\%), cuya existencia solo se puede constatar mediante la radiografía.

Como se observa, el análisis cualitativo de la documentación asociada a las placas reveló que la categoría más estudiada en las pinturas de caballete, intervenidas en los talleres de restauración, se refiere a la técnica de ejecución (70 \%), lo cual permite al investigador conocer detalles 
pictóricos sobre cómo se prepara el lienzo, los primeros trazos de ese dibujo preparatorio y el uso de pinceladas finas para la ejecución de rostros, manos (imágenes 12 y 13) y pies, por ejemplo.

Así mismo, este proceso metodológico de análisis condujo a clasificar la información para luego categorizar por unidades temáticas las interpretaciones de las placas radiográficas. Esto se hace posible a partir de patrones dados por los aspectos radiológicos, brindando herramientas para el establecimiento de la autenticidad de una obra pictórica con base en una grafía particular.

A su vez, esa correlación de los datos científicos, comparando técnica, trazos, disposición de luces e iluminación del dibujo, revela, de una manera práctica, la utilidad de documentar una grafía determinada al brindar los patrones inequívocos para la identificación de pinturas no firmadas y con ello construir un archivo con estos patrones.

Esta metodología conduce a armar conexiones entre los conceptos teóricos y los conceptos que emergen de las interpretaciones de las pinturas de caballete expuestas a los rayos $X$. Con estas herramientas de análisis, cada especialista, entre los que se destacan historiadores del arte, curadores y científicos especializados en un autor o escuela, puede realizar comparaciones con otras obras firmadas y llegar a apreciar detalles característicos del artista al ser una fiel huella dactilar.

\section{Consideraciones finales}

De acuerdo con las corrientes actuales del patrimonio digital, según Lutz (2018) “lo que no está en línea, no existe” (p.3), es lo que motivó a pensar cómo llegar a diseñar una herramienta, a partir del análisis cualitativo de datos, que lograra agrupar y relacionar diversa documentación gráfica con la información científica que caracteriza la materialidad de bienes muebles como las pinturas de caballete de los siglos XVII, XVIII, XIX y XX, estudiadas en la Universidad Externado de Colombia.

Para la construcción del SICAP, se identificó y se localizó la información (inédita) dispersa y disociada de las 120 obras de pintura de caballete. Ello implicó revisar una a una las 211 radiografías, las 617 fotografías en plano físico y otra cantidad similar de fotografías en digital, rastreando y localizando los 390 cortes estratigráficos para repetir cientos de microfotografías y registrar en cada uno de los informes de resultado de los análisis efectuados por los químicos que las estudiaron. En esta base de datos, SICAP, encontrarán cientos de resultados de los análisis científicos agrupados en un sistema, haciendo relaciones bidireccionales 
correspondientes a la naturaleza de las fibras de los lienzos, la composición de 66 bases de preparación y la composición elemental de 287 pigmentos orgánicos e inorgánicos que imprime colores representativos para ciertas épocas.

Fue preciso transformar toda esta información en datos para su uso en el SICAP. Creando una herramienta que es capaz de ir más allá de los análisis de la temática iconográfica al vincular análisis globales (como radiografías de óptima resolución, con las cuales es posible obtener el patrón radiológico) $\mathrm{y}$, por medio de ellos, cotejar la grafía al relacionar con la composición de la materialidad de cada una de las obras firmadas o atribuidas a diferentes artistas. A partir de las clasificaciones de cientos de resultados, luego de codificar la documentación técnica, los usuarios pueden reutilizar y transformar los datos en categorías y metadatos, relacionar temáticas y categorías iconográficas junto con la naturaleza de los materiales, asociados en un mismo sistema. De esta manera, se pueden realizar un conjunto de reflexiones, transformaciones y comprobaciones de los datos, con la que se logran extraer significados referentes a la conservación de obras de arte o de patrimonio material, construir conceptos densos y así proyectar nuevas investigaciones.

Con la metodología empleada para la construcción de bases de datos a partir de investigaciones realizadas por los científicos que estudiaron y analizaron la materialidad de las pinturas de caballete, se hizo un puente con los métodos cualitativos de las ciencias sociales para organizar la información por medio de mapas y esquemas conceptuales. Con estos se logró configurar una base de datos relacional que permite el análisis de la información para que cada usuario organice y categorice volúmenes de archivos ya sintetizados en esta novedosa propuesta materializada en el producto SICAP.

Con este enfoque se usó la teoría fundamentada, muy específicamente para la construcción de la metodología, así como de esta herramienta de trabajo para la investigación y producción de conocimiento. Al mirar cómo hacer su uso hacia otros ámbitos académicos, hay un segundo nivel de abstracción del uso de la teoría fundamentada y es poder empezar a teorizar en la medida que se siga con este trabajo de investigación, creando grupos de estudio con los mismos estudiantes del pregrado de conservación y restauración con los que se siga alimentando el sistema e ingresando otros bienes: escultura policromada, pintura mural, bienes gráficos, cerámica arqueológica, etc. A partir de todos esos datos empíricos obtenidos del patrimonio material colombiano se podrá hacer comparaciones constantes, analizando los datos una y otra vez, durante años, hasta llegar al punto de saturación para construir conceptos. Esos significados que puedan ser usados desde una narrativa científica y social que permita conducir a la construcción de 
nuevas teorías y que todas las disciplinas desde un historiador del arte hasta un especialista en arqueometría, puedan usar los términos universalmente.

Así, con elSICAP se estaría incursionando en el tema de las humanidades digitales con una propuesta contemporánea que permitirá la divulgación de contenidos científicos a través de una web institucional, como lo es la biblioteca digital, con el respaldo de la Universidad Externado de Colombia, lo que garantiza la robustez del servidor y asegura la preservación de la información y sostenibilidad en el tiempo. Hay que mencionar, también, que se está participando en mesas de trabajo con el departamento de propiedad intelectual de la universidad para solventar el tema jurídico por medio del modelo de gestión de derechos de autor, para garantizar la difusión sin restricción en la web.

\section{Referencias bibliográficas}

Álvarez, M.C. (2005). Los Rayos X y el arte. Estudios de autoría. En M. Fajardo de Rueda y UN Colombia (Ed.), Tesoros artísticos del convento de las Carmelitas descalzas de Santafe de Bogotá (pp. 37-43). Bogotá, Colombia: Universidad Nacional de Colombia.

Arellano, J. y Santoyo, M. (2009). Investigar con mapas conceptuales: procesos metodológicos. Madrid, España: Narcea Ediciones.

Borja, J.H. (2013). Temas y Problemas en la pintura colonial neogranadina. Quiroga: Revista de Patrimonio Iberoamericano, 3, 26-38.

Bravo, M. (2008). Políticas culturales en Colombia. En A. Rubim y R. Bayardo, Políticas culturais na Ibero-América (pp. 119-158). San Salvador, El Salvador: EDUFBA.

Chagoyán, G., Coronel, L. y Figueroa, I. (2013). Los soportes de madera en esculturas policromadas mexicanas, restauradas en la ENCRyM. Intervención, 2, 34-45.

De Norden, I. (6 de agosto de 2014). De Colcultura al Ministerio. Revista Arcadia. Recuperado de https://www.revistaarcadia.com/especiales/especial-mincultura-/articulo/de-colcultura -al-ministerio/38242

Giraldo Prato, M. (2011). Abordaje de la Investigación Cualitativa a través de la Teoría Fundamentada en los Datos. Ingeniería Industrial. Actualidad y Nuevas Tendencias, II (6), 79-86.

Giró, S. (2010). Sistemas digitales de adquisición de imágenes visibles, infrarrojos e hiperespectrales. En Ministerio de Cultura. (Ed.) La Ciencia y el Arte II: ciencias experimentales y conservación del Patrimonio Histórico, 205-214. Madrid: Ministerio de Cultura.

González, A. (2013). La reflectografía infrarroja y la historia del arte. En Ministerio de Cultura (Ed.), La ciencia y el arte IV. Ciencias experimentales y conservación del patrimonio (pp. 163-177). Madrid. España: Ministerio de Cultura.

Guerrero, K., Villaveces, S. y Murcia, F. (2017). ARCA® Cultura visual de las américas coloniales. Recuperado de http://157.253.60.71:8080/

Hayles, K. (2012). How we think: Digital media and contemporary technogenesis. Chicago: U.S.A.: University of Chicago Press.

Ineba, P. (2010). Aplicación de los estudios físicos en el campo de la restauración. En Ministerio de Cultura. (Ed.) La Ciencia y el Arte II. Ciencias experimentales y conservación del Patrimonio Histórico, 71-78. Madrid: Secretaría General Técnica. Ministerio de Cultura. 
Lleras, R. (2014). La producción del patrimonio cultural restaurado. Boletín de historia y antigüedades, 101(859), 381-397.

Lutz, S. (2018). From cultural to digital heritage. Hamburger Journal FüR Kulturanthropologie (HJK), 7, 3-23. Recuperado de https://journals.sub.uni-hamburg.de/hjk/article/view/1190

Morales, H. y Arango, M. (1979). La radiología en la pintura santafereña del siglo XVII. Medicina, 2(2), 39-54. Recuperado de https://revistamedicina.net/ojsanm/index.php/ Medicina/article/view/3-4

Pesantez, Á.M. (2001). Acercamiento metodológico para la lectura e interpretación de rayos X en pintura de caballete. Colección pictórica de la Iglesia de la Orden Tercera Franciscana en Bogotá (tesis de pregrado). Universidad Externado de Colombia, Bogotá.

Rodríguez, D.A. (1995). Materiales de la pintura de caballete en el Nuevo Reino de Granada (Documento Inédito). Bogotá: Colcultura - ICETEX.

Ruvalcaba, J. (2008). Las técnicas de origen nuclear: PIXE y RBS. En Ministerio de Cultura. (Ed.) La ciencia y el arte: ciencias experimentales y conservación del Patrimonio Histórico (pp.151-172). Madrid: Ministerio de Cultura.

Strauss, A. y Corbin, J. (2002). Bases de la investigación cualitativa. Técnicas y procedimientos para desarrollar la teoría fundamentada. Universidad de Antioquía: Colombia.

Suárez, J. y Sancho-Caparrini, F. (s.f). The Baroque Art Project: A data collection of Hispanic Baroque painters and paintings from 1550 to 1850. Recuperado de http://www.cultureplex. $\mathrm{ca} /$ project/the-baroque-art-project-at-your-service/

Vargas, L. (2012). Del pincel al papel: fuentes para el estudio de la pintura en el Nuevo Reino de Granada (1552-1813). Bogotá, Colombia: Instituto Colombiano de Antropología e Historia.

Vidal, M. (29 de julio de 2012). La Salvadora de las obras de arte de los grandes maestros. Diario El País. Recuperado de http://www.elpais.com.co/entretenimiento/cultura/lasalvadora-de-las-obras-de-arte-de-los-grandes-maestros.html

Vinck, D. (2013). Las culturas y humanidades digitales como nuevo desafío para el desarrollo de la ciencia y la tecnología en América Latina. Universitas H umanística (76), 51-72. 


\section{Imágenes referenciadas}

\section{Toma de muestras a pintura de caballete, estudiada e intervenida en el año 2012}

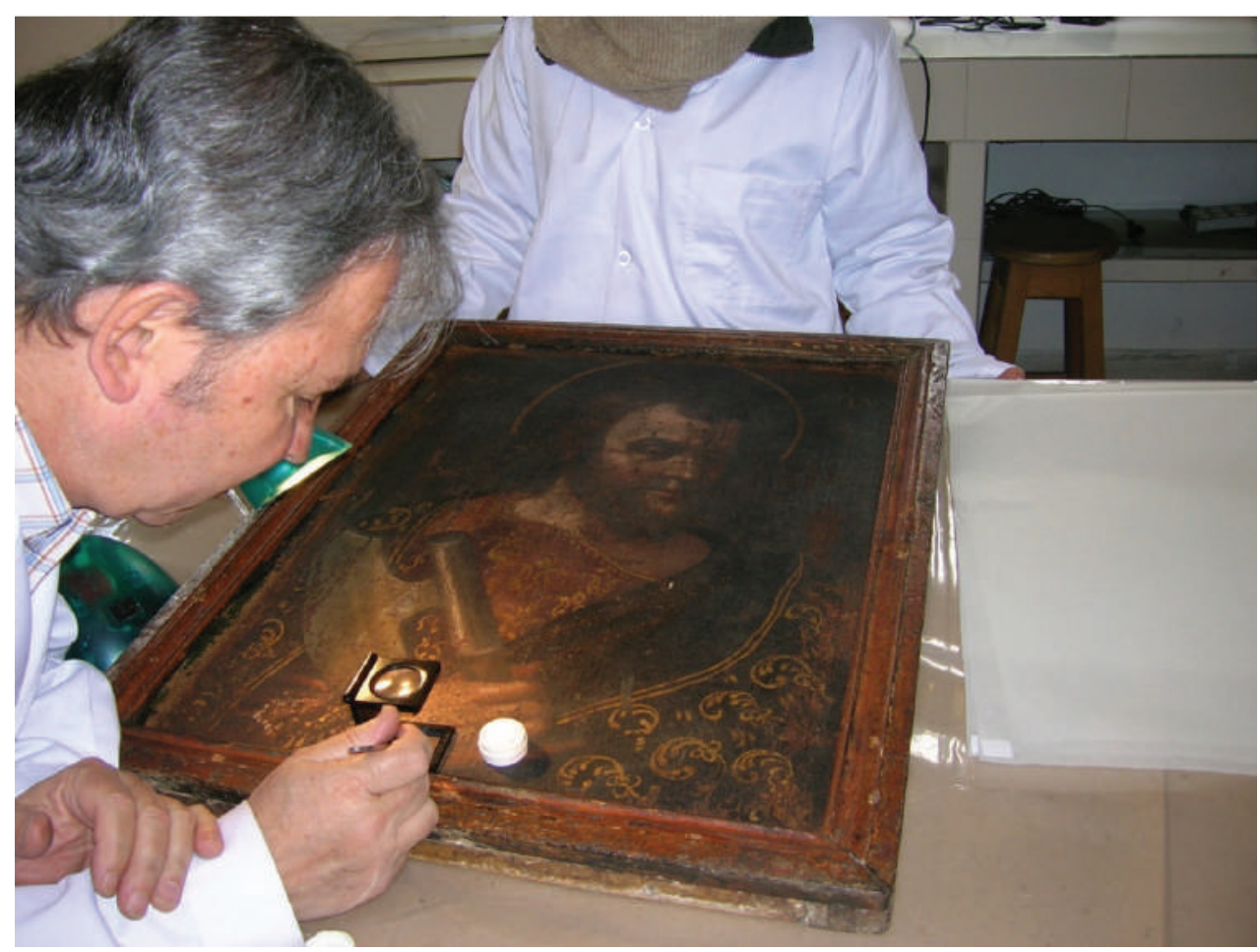

Imagen 1. El analista químico Javier Uribe Suárez, tomando muestras de la pintura de caballete con código 482-2012, título: San Matías, óleo sobre lienzo, siglo XVIII. Autor desconocido.

Tema iconográfico: Santos y santas, categoría: Santos masculinos, de Iglesia primitiva, apóstol. Fuente: Jhon Garcés (2012). 


\section{Banco de muestras de cortes estratigráficos de patrimonio material colombiano}

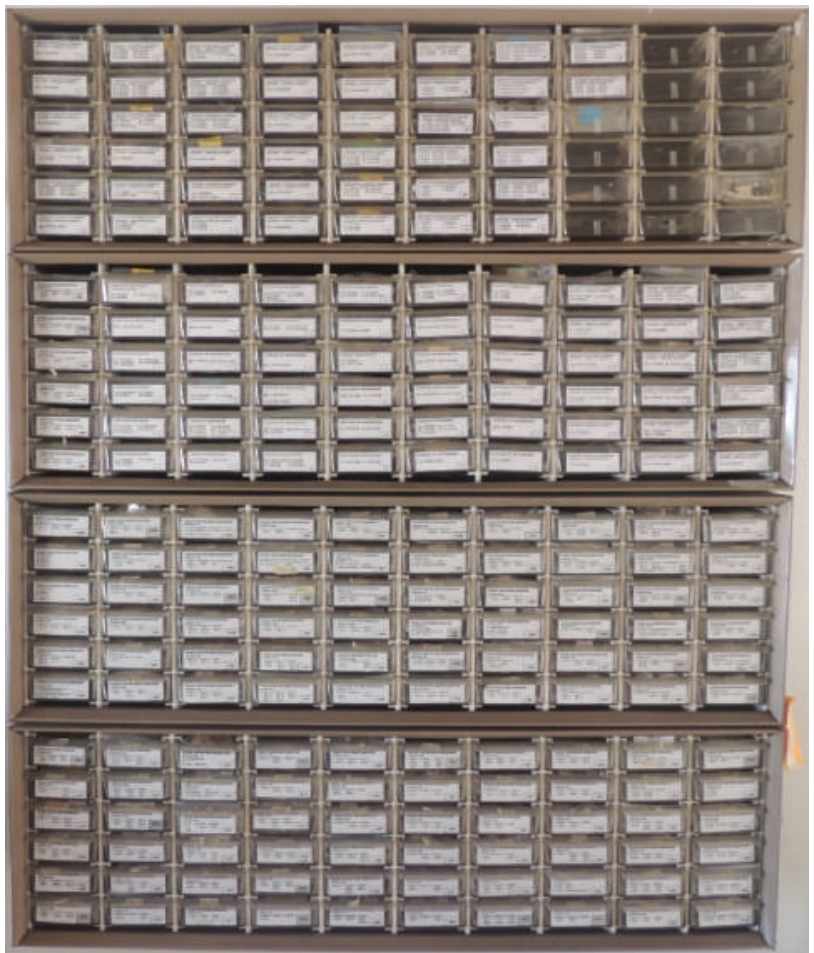

Imagen 2. Banco de muestras de cortes estratigráficos entre ellas 350 pinturas de caballete del CNR, desde 1975 hasta 1995. Además de cortes de escultura, pintura mural, sumado a las 120 pinturas de caballete estudiadas en los talleres del pregrado desde 1999 hasta 2014.

Fuente: Jhon Garcés (2018). 
Arte, patrimonio y la pérdida de conocimiento de la pintura de caballete en Colombia... |

Comparación de bases de preparación de dos obras firmadas de artistas locales del siglo XVII

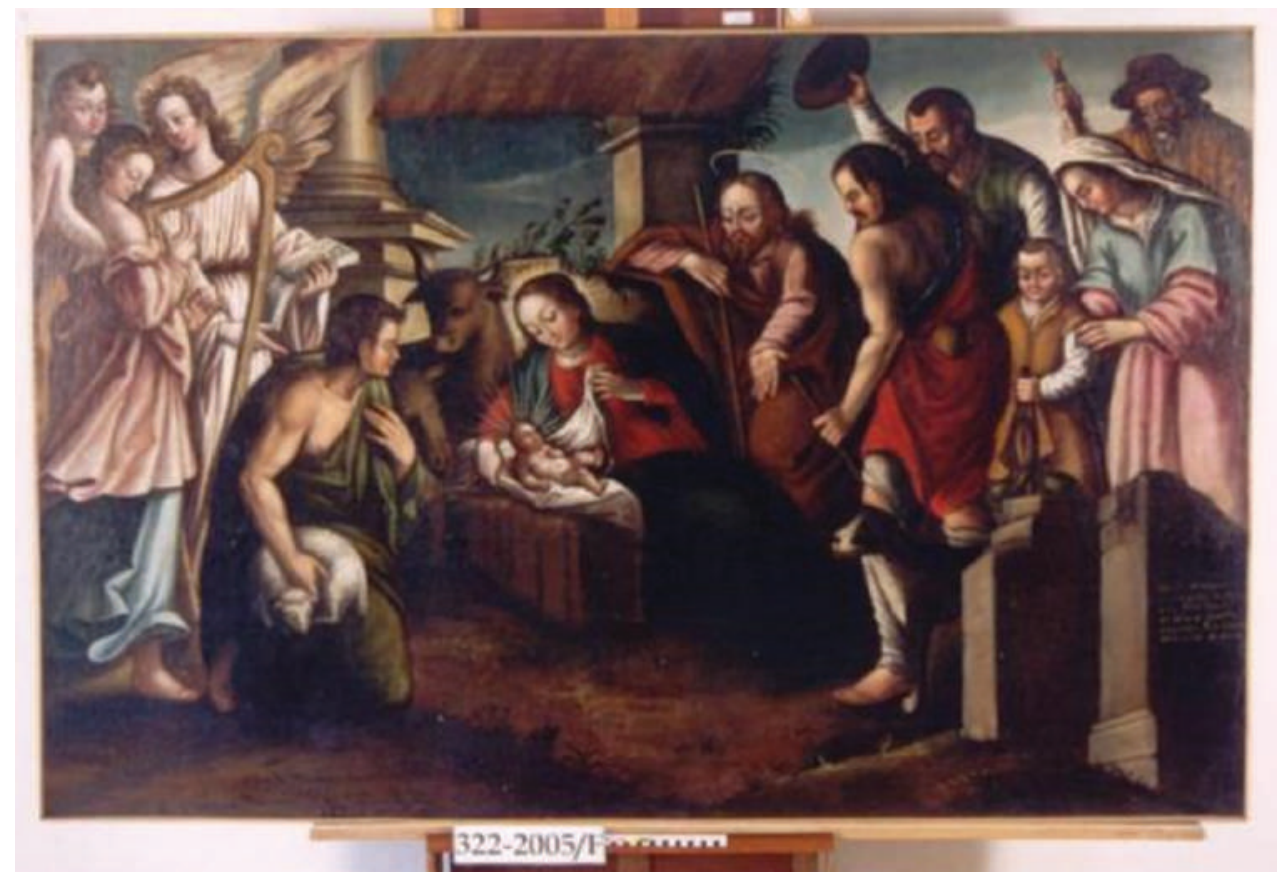

Imagen 3. Pintura de caballete código: 322-2005. Título: La Adoración de los pastores. Autor: Antonio Acero de la Cruz (Firmado).

Fuente: Centro de documentación, Facultad de Estudios del Patrimonio Cultural. UEC 


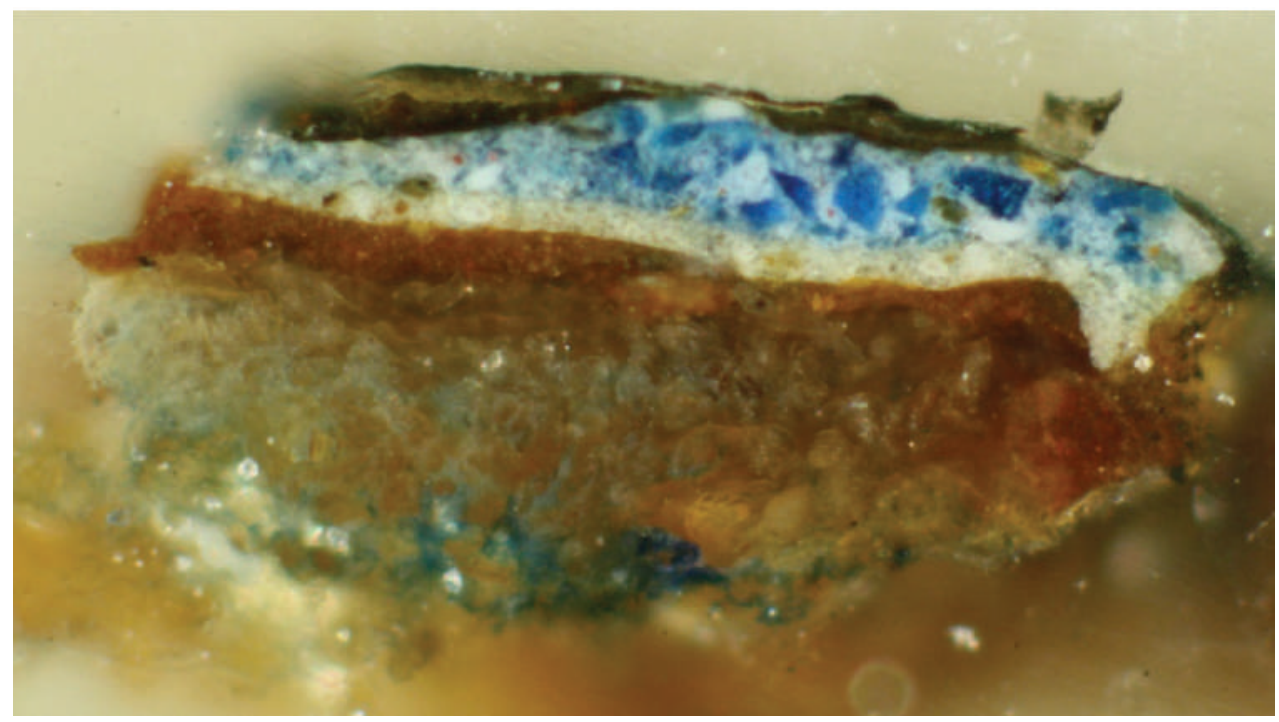

Imagen 4. Corte (322-III-01-2005) tomado de la zona de color verde-azul, correspondiente a vestiduras. Base de preparación: Hematita (tierra roja) aglutinada con aceite. 20-60 $\mu$. Fuente: Jhon Garcés (2018).

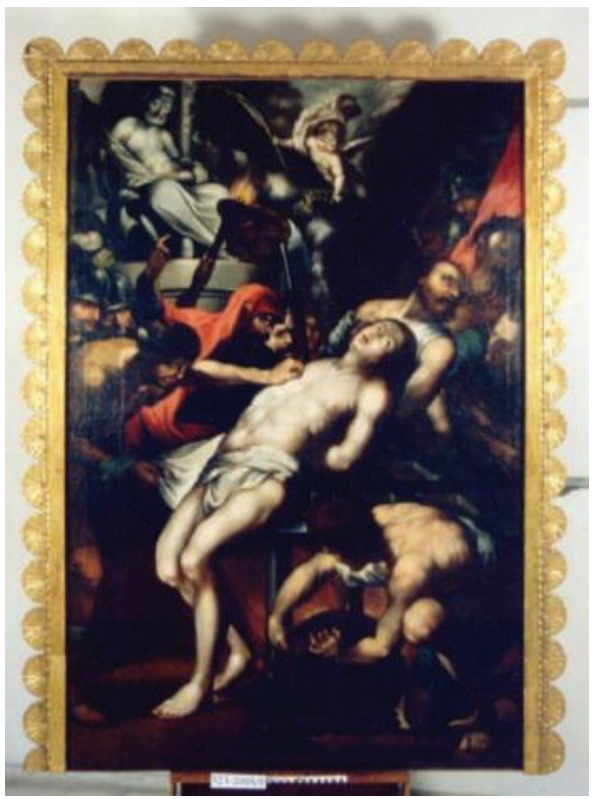

Imagen 5. Pintura de caballete código: 323-2005. Título: El martirio de San Lorenzo. Autor: Juan Bautista Vázquez (firmado).

Fuente: Centro de documentación, Facultad de Estudios del Patrimonio Cultural, Universidad Externado de Colombia. 
Arte, patrimonio y la pérdida de conocimiento de la pintura de caballete en Colombia... |

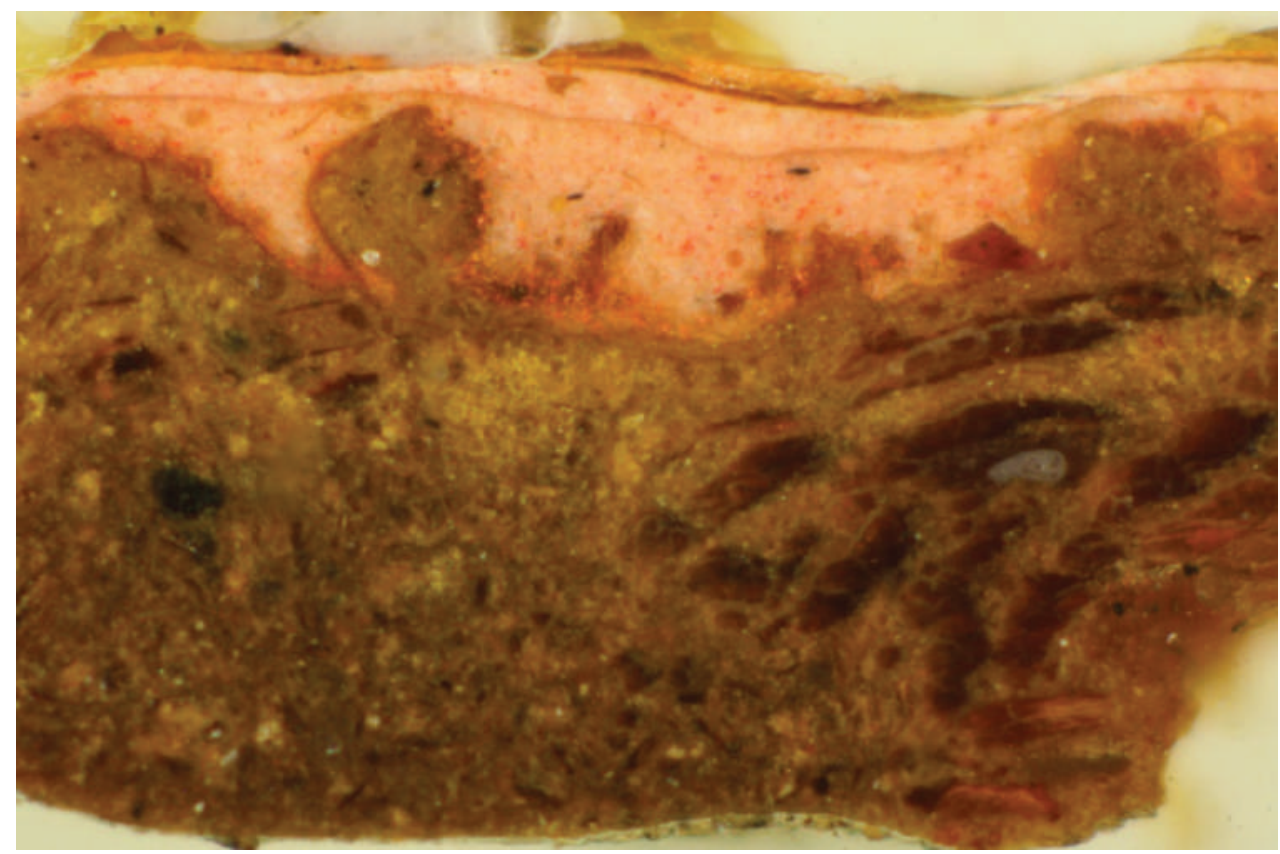

Imagen 6. Corte (323-III-01-2005) tomado en la bandera (Color rojo) parte superior derecha de la obra. Base de preparación: Limonita (Ocre amarillo) aglutinada con aceite. $450 \mu$ aprox. Fuente: Jhon Garcés (2018). 


\section{Microfotografías de cortes estratigráficos, insertos en el segundo cuerpo del SICAP}

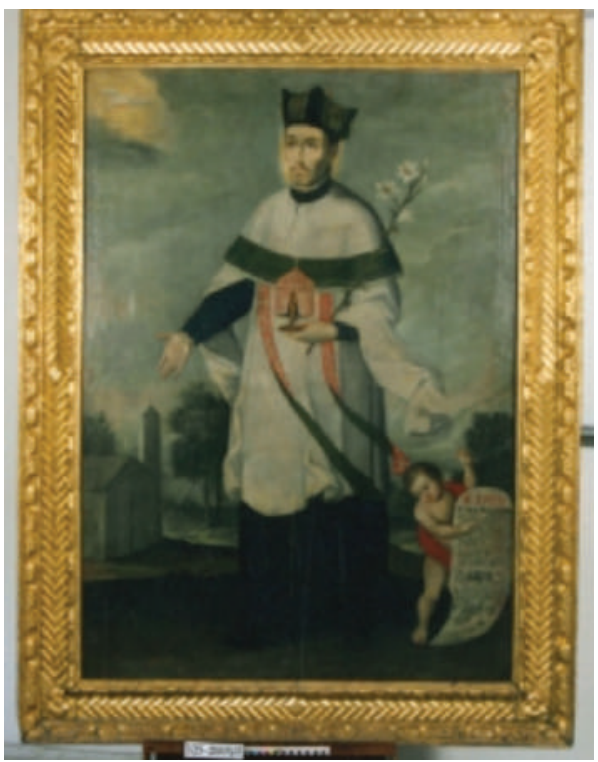

Imagen 7. Obra 325-2005. Temática iconográfica: Santos mártires, San Ivon de siglo XVIII. Autor: Camargo. Corte tomado de la zona correspondiente al celaje, costado izquierdo de la obra, parte superior (color azul). Fuente: Centro de documentación, Facultad de Estudios del Patrimonio Cultural; Universidad Externado.

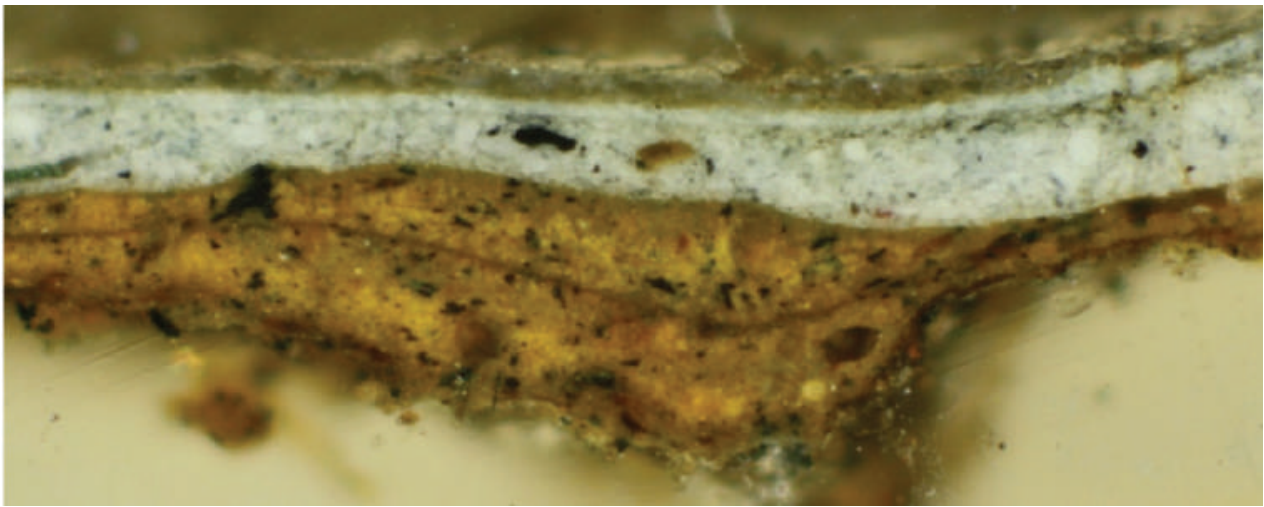

Imagen 8. Microfotografía del corte (325-III-01-2005) y su interpretación, descripción de capas pictóricas. Fuente: Jhon Garcés (2018).

Capa 5: Capa de recubrimiento $10 \mu$. Capa 4: Capa pictórica blanca con partículas azules aglutinada con aceite. 10-20 $\mu$.

Capa 3: Capa pictórica blanca con partículas azules y negras aglutinada con aceite. 40-80 $\mu$. Capa 2. Base de preparación ocre aglutinada con aceite. 20-90 $\mu$. Capa 1. Base de preparación ocre aglutinada con aceite. $110 \mu$ aprox. 


\section{Visión en conjunto del mosaico de placas de rayos $\mathrm{X}$ e interpretación de dibujo subyacente}
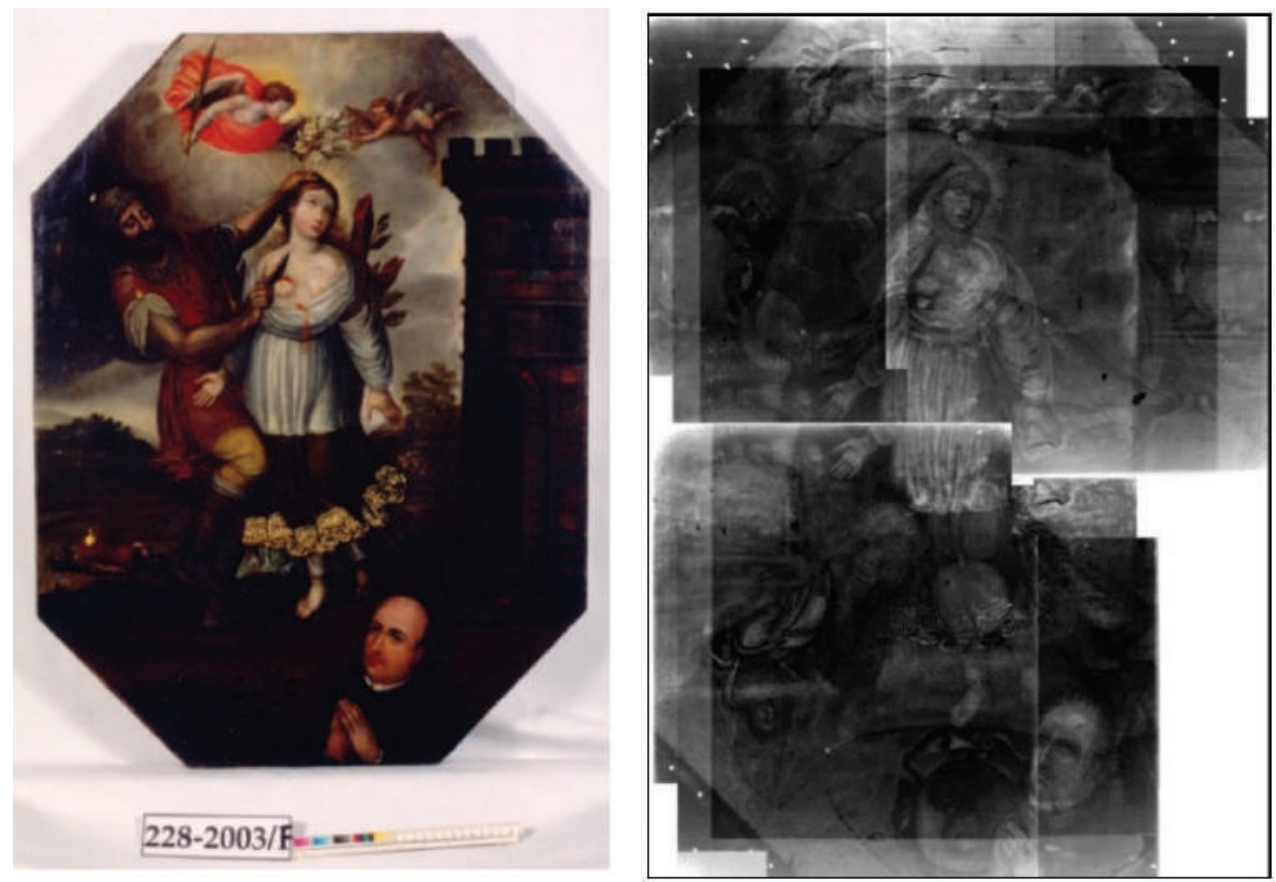

Imagen 9. Visión en conjunto del mosaico de placas de rayos X e interpretación de dibujo subyacente. Obra 228-2003. Martirio de Santa Bárbara, de siglo XVIII. Autor desconocido. Conformación del mosaico con seis placas digitalizada en imagen JPG con un tamaño de $18.2 \mathrm{mb}$

(Garcés, 2017). Interpretación de las placas de rayos X: la existencia de una pintura subyacente completa e invertida a la actual corroborando que el formato octogonal que presenta la obra es original. La obra subyacente no tiene relación alguna con la imagen que se observa actualmente, ya que se representan dos personajes a lado y lado de la obra, confirmando la reutilización de lienzos.

Fuente: Jhon Garcés (2018). 


\section{Enfoque metodológico para el diseño del SICAP}

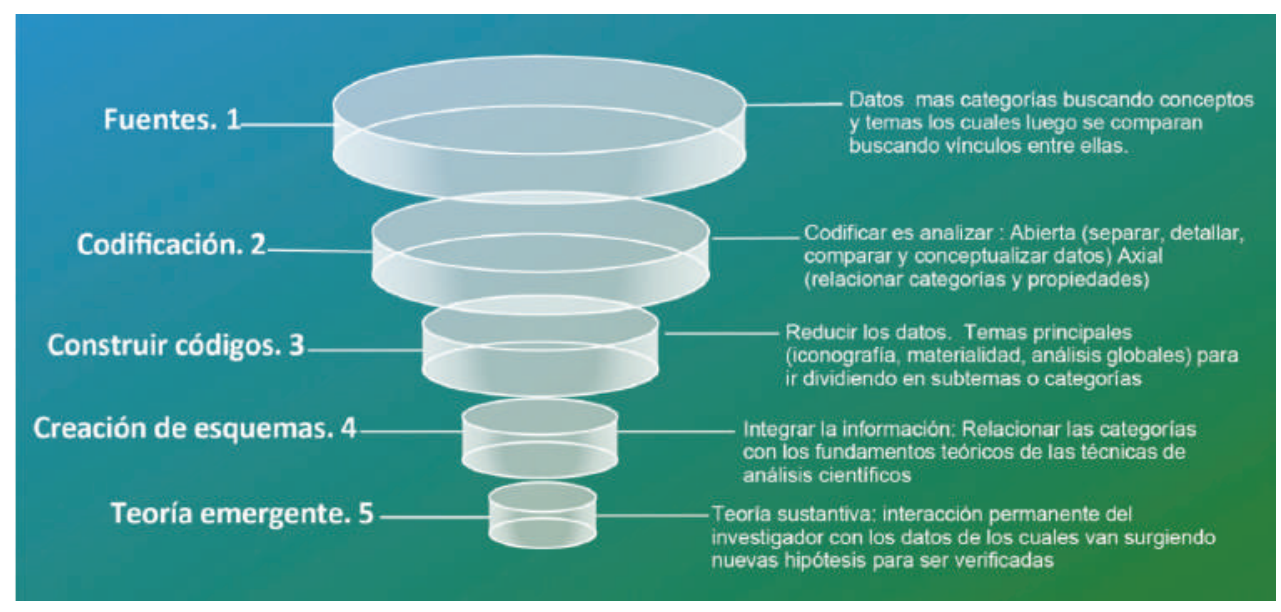

Imagen 10. Modelo mixto entre la teoría fundamentada y el análisis de datos cualitativos. Enfoque metodológico, propuesto por el autor para construir el sistema de información científica de arte y patrimonio.

Fuente: Jhon Garcés Mora (2019). 
Arte, patrimonio y la pérdida de conocimiento de la pintura de caballete en Colombia... |

\section{Placas radiográficas para realizar estudios y comparaciones de grafía del autor}

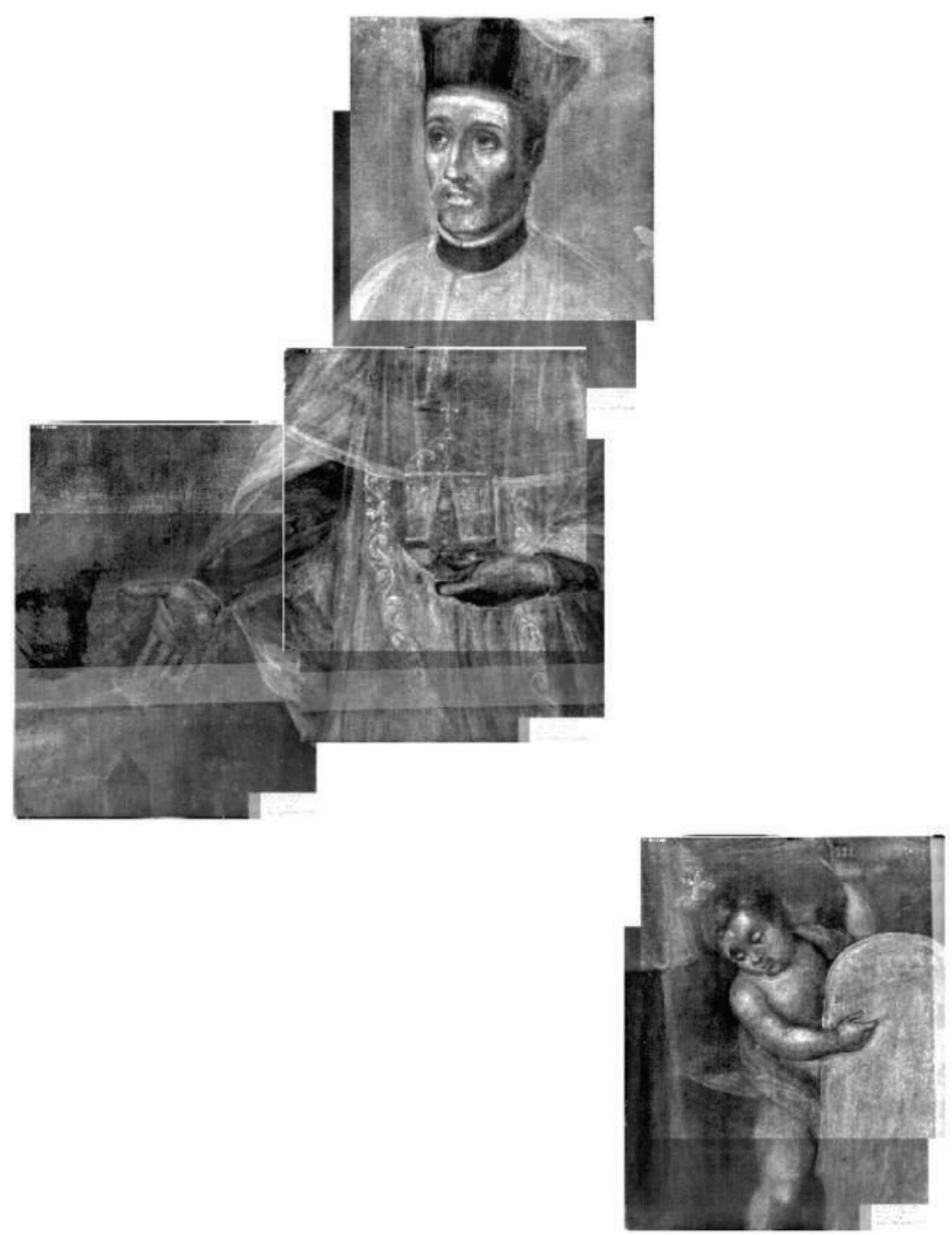

Imagen 11. Título: San Ivon. Siglo XVIII. Autor: Camargo. Mosaico 4 placas de rayos X. Uso de blanco de plomo observando el trazo compuesto por el artista. (radiografías: 43 × $35 \mathrm{~cm}$. Digitalizada a $36.1 \mathrm{mb}$. Fuente: Jhon Garcés (2017). 


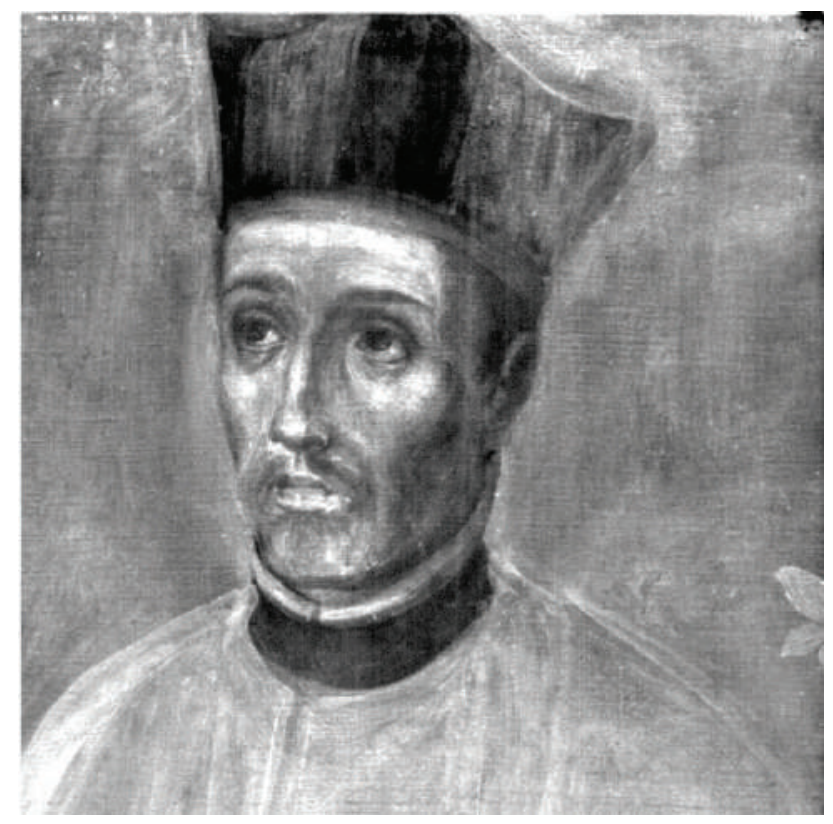

Imagen 12. Uso del blanco de plomo para lograr rostro y fondo de la pintura (radiografía en físico de 43 x 35 cm: Digitalizada a 7.80 mb. Fuente: Jhon Garcés (2017).

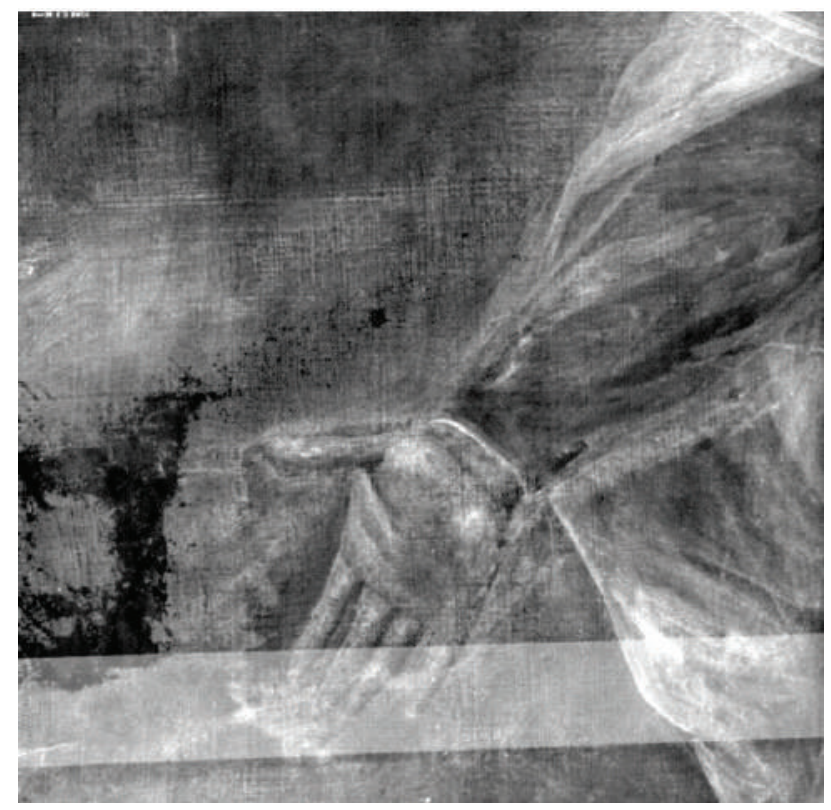

Imagen 13. Forma en la cual el artista hizo la aplicación de blanco de plomo, trazo y volumen en la mano (radiografía: 43 × 35 cm. Digitalizada a 7.33 mb. Fuente: Jhon Garcés (2017). 